\title{
Gaining a lot from translation
}

\section{Steve O'Rahilly: Dedicated clinical research facilities, which forge a link between bench and bedside, make it easier to pursue projects.}

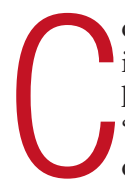
onverting basic science into clinical practice is never an easy task, and Europe is still lagging behind the United States in this 'bench-to-bedside' endeavour. The number of research centres in Europe that can offer dedicated space for 'translational research' is low, and funding for clinical scientists is difficult to obtain across the continent.

Unlike in the United States, where physicians can undergo scientific training during their education, research is rarely part of the curriculum in Europe. Germany's main research funding body, the DFG, admitted as such a few years ago in a statement, concluding that "research is still considered a spare time activity" at German academic medical centres.

In an effort to bridge the gap between basic and clinical research, the European Molecular Biology Laboratory in Heidelberg, Germany, teamed up with the University of Heidelberg Medical School and this January announced the opening of a Molecular Medicine Partnership Unit. Matthias Hentze, one of the unit's co-directors, hopes that the lab will grow to about 30 members for a pilot phase of four years. He sees the venture as an "incubator" for scientifically inclined physicians and would also like to initiate an $\mathrm{MD} / \mathrm{PhD}$ programme.

\section{FRESH FACILITIES}

In the United Kingdom, the Wellcome Trust, the country's largest biomedical charity, is contributing $£ 20$ million (US\$30.5 million) to help to establish clinical research facilities (CRFs) in an effort to ease the burdens of hospitals that find it difficult to accommodate the needs of academic research. Five CRFs - the most recent of which opened in Manchester this month have been set up as partnerships between local universities and local healthcare providers. The facilities will offer dedicated clinical space, equipment and personnel for several research labs.

For Helen Routledge, who is doing her $\mathrm{PhD}$ at the Queen Elizabeth Hospital in Birmingham, the CRF set up there in January is a major asset. She is investigating the effects of air pollution on the cardiovascular system. The improved access to equipment and the technical expertise provided by

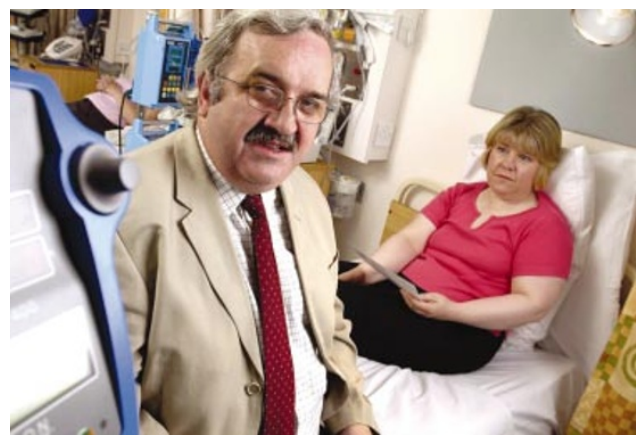

the staff, which includes a cardiac technician, are a great help, she says.

Steve O'Rahilly, who heads the CRF opened at Addenbrooke's Hospital in Cambridge this January, says that the set-up makes it much easier to conduct his research into the genetic basis of severe obesity. As well as offering patients comfortable surroundings, he says, the in-patient facility means that study volunteers can stay overnight.

\section{GROWING DEMAND}

But despite this promise, the situation still requires some juggling skills. Sadaf Farooqi, a research fellow working for O'Rahilly, is pursuing bench research in addition to her clinical duties. Although she has managed to balance her responsibilities inside and outside the lab, she is quick to point out that her situation is not typical and that there are currently "not enough fellowships to meet the growing need". Farooqi believes it will be crucial to secure funding so that she can hire some help to keep her research afloat while she is on the wards honing her clinical skills.

Simon Hart, a specialist registrar in respiratory medicine at the University of Edinburgh, UK, has successfully taken the fellowship hurdle and secured a Clinician Scientist Fellowship from the Medical Research Council. The fellowship provides $\mathfrak{E} 6,500$ a year for up to four years of support for the transition from postdoctoral fellow to independent investigator. Hart, whose research interest lies in the field of inflammatory-cell biology, is relieved that this type of funding does not force him to abandon his research project for the next four to five years while completing his medical training.

But some problems remain. Clinical scientists often face "financial penalties" for choosing research over practice, Hart says, and physicians tend to earn more than clinical researchers. Although the new CRFs are attracting more translational researchers, the salary gap may mean a continuing shortage of suitably trained candidates for academic clinical investigator positions. Unless new schemes emerge to make up the difference, it is likely that physician scientists will heed the call of clinical practice rather than translational research. Jan Schmollinger is a graduate student in Boston.
Web links Medical Research Council www.mrc.ac.uk Wellcome Trust www.wellcome-ac.uk European Molecular Biology Laboratory

www.emblheidelberg.de 